\title{
TWO AXES SUN TRACKING SYSTEM: COMPARSION with a FIXED SYSTEM
}

\author{
M. Serhan and L. El-Chaar \\ Department of Electrical Engineering \\ Petroleum Institute \\ PO BOX 2533, Abu-Dhabi (UAE) \\ Phone/Fax number:+00971 6075503, e-mail: mserhan@pi.ac.ae, lelchaar@pi.ac.ae
}

\begin{abstract}
.
In this paper, a sun tracking system is designed and built using a simple mechanical structure and control method. A comparison is carried out between a fixed solar system and the tracking system to emphasize the increase in the energy produced. The tracking system reliability is also tested for diverse weather conditions.
\end{abstract}

\section{Key words}

maximum power point, photovoltaic, solar energy, dc drives, renewable energy.

\section{Introduction}

The world trend nowadays is to find a non-depletable and clean source of energy. Non-renewable energy, obtained from exhaustible fossil fuels, is no more satisfactory to many nations. Not only the resources (coal, oil \& natural gas) are subject to be severely reduced, but also they are considered to be non-secure; wars and politics afflict its availability and cost [1]. Moreover many environmental organizations address this energy production scheme as the main contributor to pollution and global warming [2].

This concern for our diminishing resources and environmental balance suggest a strong interest in indigenous and renewable sources of energy. At the same time the limitations of centralized grid-supplied electricity in covering the greater part of the rural world have become obvious and demand a flexible, decentralized approach.

Solar electric concepts have proven to offer a viable solution to the imminent problems [3].

Although many solar thermal energy power plants (large scale 'MW') are already installed and operational, yet photovoltaic solar cells used for domestic applications (small scale 'KW') are more spread and used. You can always find traffic and street lights, water pumping and distillation systems, and food cooking techniques that operate on solar power. Remote villages in developing countries miss the municipality electric power, so people depend on solar cells to generate electricity to activate their simple appliances like radios, TVs, sewing machines, etc [4]. People in developed countries are also convinced to install PV systems to benefit from selling their extra solar electrical power to the electric companies. Moreover efficiency enhancement and cost reduction of PV panels and their direct applications like powering White led, encourage people to mount solar panels at their homes [5].

The PV panels are usually mounted on the roof of the house or at a near open area to face the sun. The custom is to fix these solar modules position angle to the country latitude angle. If possible, seasonally some people try to adjust the module's direction manually towards the sun. However to collect as much solar radiations as possible, it is more convenient and efficient to use a sun tracking system. In photovoltaic tracking systems, the surface of the module tracks the sun throughout the day.

The tracking can be along either one or two axes whereby tracking along two axes provides a higher power output. The energy yield can be thus increased by around $20 \%$ up to $30 \%$ depending on the seasonal climate and geographical location [6-8]. Although some people claims that a fixed system costs less and requires almost no maintenance [1], different tracking mechanisms are utilized to control the orientation of the PV panels, of which most proved their superiority over fixed system in terms of converted power efficiency.

One method makes use of photoelectric sensors to generate an error signal whenever the position of the panels is not ultimate. Driving the system motors, this signal reorients the panels' direction toward the sun via a feedback mechanism $[9,10]$. Some authors claim that this mechanism is not reliable under foggy and cloudy weather conditions [11]. Another tracking is achieved by deriving the equations of motion for the earth with respect to the sun. Then based on these equations, the automated system directs the panels all day long [12]. However this automated system will stay 
operational even if the weather is cloudy and there is no sun to track; thus spending stored energy without gaining any. The same issue rises when a clock mechanism is used. An onboard clock is used with the help of other stored parameters to compute the sun position angles. The angles are transformed to coordinates that drive the tracker [13]. Another alternative is to have a database for the correct angle of incidence for the solar rays of one country stored and this stored data sets the solar panel position round the clock. Usually such systems are expensive and complex based on the requirement for the database storage media and clock accuracy.

In this paper the first mechanism is promoted and enhanced to overcome the issues related to (cloudy, rainy ...) weather conditions. To prove the system reliability and efficiency, a comparison is carried on between this system and another fixed one for the aforementioned conditions.

\section{Tracking System Design}

The system tracks the sun autonomously in altitude and azimuth. Two ac motors move an 80 watts panel mounted on the mechanical structure as shown in Fig. 1and Fig. 2. It requires no human interface where four attached sensors are continuously updating a PIC microcontroller which in return controls the rotations of the motors.

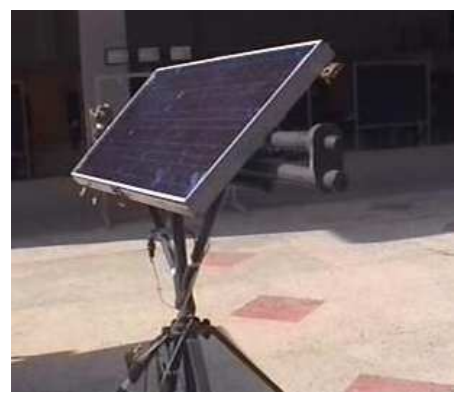

Fig. 1: Panel mounted on mechanical structure.

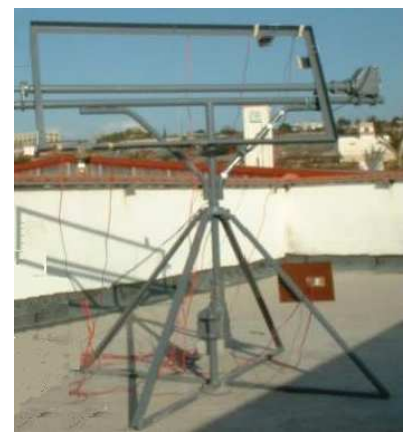

Fig. 2: Rigid body of the tracking system. A. Mechanical Design
Fig. 3 represents the mechanical structure of the tracking system. The horizontal axis rotates the panel from east to west and the vertical from south to north, thus our system has two degrees of freedom. The hinges facilitate the revolution of the axes. The frame is designed to hold the desired solar panel and the base support the whole rigid body.

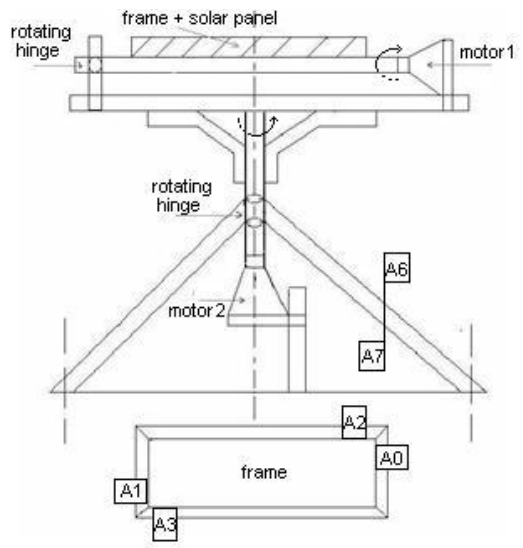

Fig. 3: Mechanical structure.

\section{B. Motors and Driver}

The motors used to rotate the axes are ac antenna motors (Fig. 4). They are pretty known for their long service life and their wind and rain withstanding potential. The tight seal will prevent water from penetrating to the inside. The rugged aluminum casting maintains greatest strength in high stress areas. Their large bearing surfaces and strong reinforced mast support lateral loads. Ball bearing is provided to hold the thrust (vertical) loads. The more important features of these motors are their high torque capabilities and precision in positioning. Almost all houses in cities, where TV/FM broadcasting is available, have one setup using this type of motors. So usually it is cheap and abundant in the market and people can easily maintain it.

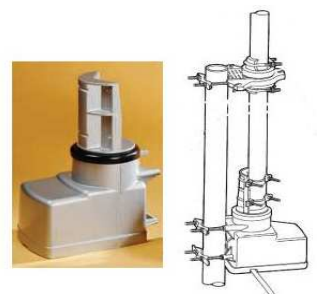

Fig. 4: Motor housing and tie arrangement.

The antenna motor is usually equipped with control set to rotate it indicating the position. However it is driven by a manual control knob while the tracking system requires a 
totally automatic control driver. Fig. 5 shows the alternative circuit used to drive the winding of each motor.

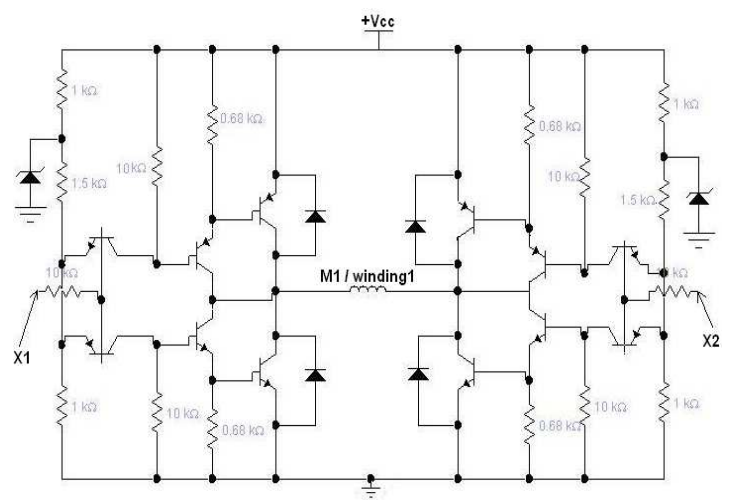

Fig. 5: Driver circuit for motor winding.

The switching bridge will provide an alternating signal across the winding of the motor. The circuit is fed by the $18 \mathrm{~V}$ of the solar panel to provide almost $1 \mathrm{~A}$ load current. The two input signal $\mathrm{X} 1$ and $\mathrm{X} 2$ are managed by the microcontroller and logic circuit. Their role is to switch on/off and invert the rotation direction of each motor.

\section{Logic Design}

Two multiplexers, a counter and ' 555 ' timer (Fig. 6) are used to organize the switching mode of the bridge to generate the pulsating signal on the windings of each motor. The two (4 -1) multiplexers are used to accomplish the different levels of the waveforms that will appear across the windings. For instance MUX1 will put on its output line bit 1 to build the 1st winding waveform, while MUX2 will output bit 0 to build the 2 nd winding waveform thus shifting it by 90 degrees as illustrated in Fig. 7. The next instance MUX1 outputs bit 1 and MUX 2 outputs bit 1 and so on.

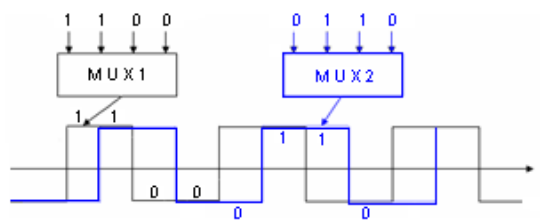

Fig. 7: $90^{\circ}$ shifted waveforms.

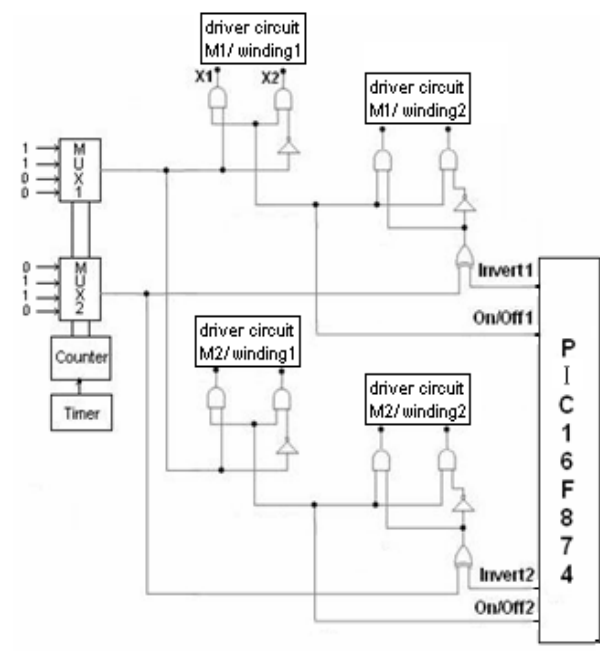

Fig. 6: Logic circuit.

The On/Off signal will activate or deactivate the two motors. In case of cloudy weather these signals (On/Off1 and On/Off2) will switch off both motors. The Invert signal along with the XOR gate will reverse the rotation direction of the respective motor. Fig. 8 shows the waveforms when the invert signal is activated.

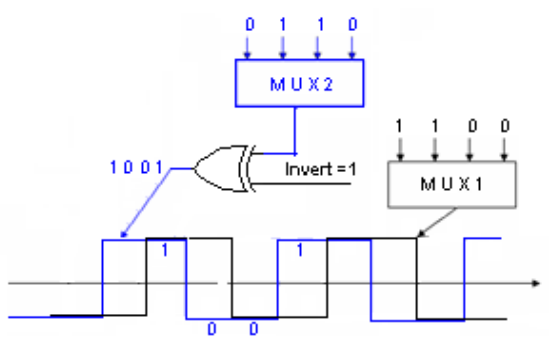

Fig. 8: Waveform flips when Invert signal is on.

The 555 timer in Fig. 6 is used to provide a clock of $100(\mathrm{~Hz})$, which will be divided by 4 with the help of the counter (it counts from 00 to 11 ) to produce a waveform with frequency of $25 \mathrm{~Hz}$ at the output of the multiplexers. This $25(\mathrm{~Hz})$ is needed with $\mathrm{V}_{\mathrm{cc}}=18(\mathrm{~V})$ to drive the motors at a lower rotational speed than the motor rated but with similar torque. The lower speed is needed for more precision in controlling the position of the motor rotation.

\section{Microcontroller}

Since the whole system is to be implemented for real life application, it is not feasible to have a PC to control your system. The cost will increase and the PC crash is not predictable. Using a PIC microcontroller chip (16F874), the cost will be less (no PC), and crashes of PC could be 
avoided. Moreover the PIC (a small IC) will occupy a small area as compared to a PC.

The 'On-Off 1' \& 'On-Off 2' and 'Invert 1' \& 'Invert 2' signals are totally controlled by the PIC micro-controller algorithm. Thus the PIC chip will tell each motor when to rotate 'On-Off' and in which direction 'Invert'.

The PIC will gather information from 4 phototransistors (A0, A1, A2, and A3) connected on the frame and 2 others (A6, A7) connected to the base support (Fig. 2, 3) and according to the readings of these phototransistors it will rotate the motors.

\section{E. Phototransistor}

The phototransistor operation is very simple. When the phototransistor is not facing light, its ohmic resistance will be high preventing current to flow, thus the average voltage across the $100 \mathrm{ohm}$ resistance will be around $1(\mathrm{~V})$ due to reflection (Fig. 9). When light strikes the phototransistor it will reduce its ohmic resistance thus allowing more current to flow and producing around $4(\mathrm{~V})$ average.

The PIC program will detect this difference in voltages due to light or darkness; thus driving the two motors through the 4 control lines ('On-Off 1', 'On-Off 2', 'Invert 1', \& 'Invert2'). The variable resistance role is to increase or decrease the sensitivity of the phototransistors. It is quite important to include this variable resistance to prevent the system from fluctuating for tiny change in sunlight radiations.

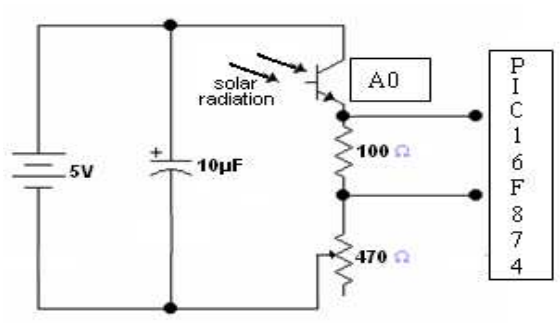

Fig. 9: Phototransistor circuit.

\section{F. Implemented Algorithm}

The program will collect data from all phototransistors. Priority is given to the bottom motor M2 (Fig. 3). So after checking A0 \& A1, the program will rotate the motor M2 towards the phototransistor with less voltage reading until both readings of $\mathrm{A} 0$ \& $\mathrm{A} 1$ are equal. Thus it will be directing the module to the max vertical receiving light position. Then the program goes to check for phototransistors A2 \& A3. This time it will rotate the upper motor (M1) again towards the one with less voltage readings until both readings are equal. Thus it will be directing the panel to the max horizontal receiving light position.
This loop continues on and on, till time of sunset where the whole module is facing the sun and is settled towards the sunset direction. At sunshine all four phototransistors are out of light beam reach, so here the need for two more phototransistors A6 \& A7, connected to the rigid base support, raises. These two phototransistors will take control now to redirect the module toward the sun. Then handle the control back to the old loop governed by A0 \& A1. To ensure that the system will not fluctuate for small different voltage readings, the program is built to respond to quarter change in both readings i.e. if (A7-A6> [A7]/4), then it is ok to run the program and start tracking, if not observe this quantity (A7-A6> [A7]/4) until it is satisfied.

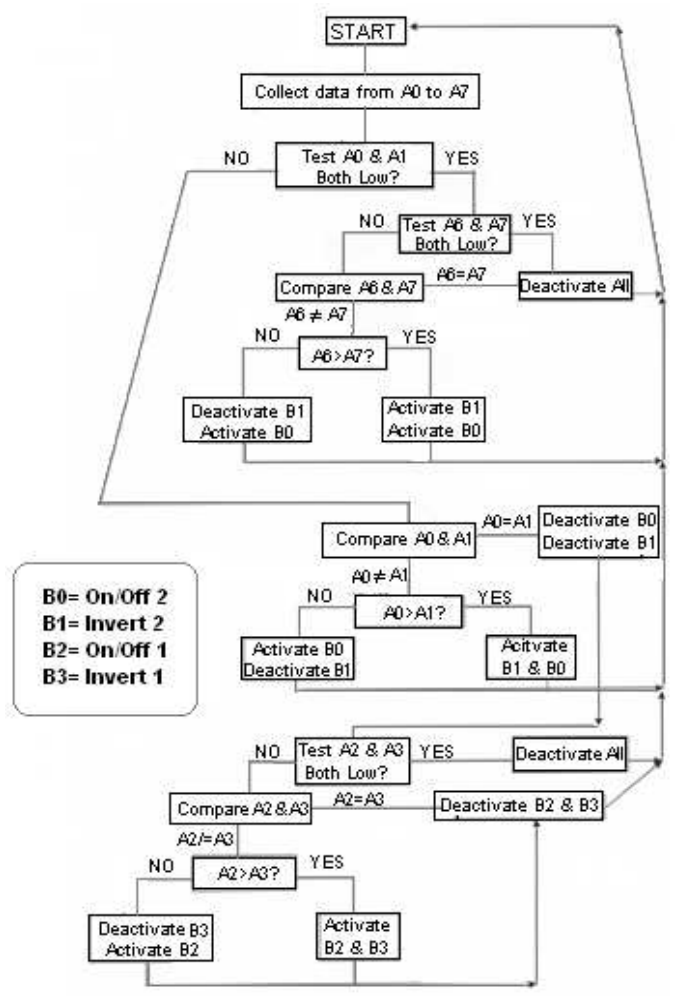

Fig. 10: Algorithm Chart.

\section{Experimental Setup}

The two setups (tracking, fixed) are set on the roof of university building. Both are located where no object or shadow will obstruct the sun light. The fixed panel is inclined according to the latitude angle $\left(33^{\circ}\right)$ of Lebanon towards the sun arc.

Both systems' panels have the same rating and manufacturer. They are interfaced through the computer 
serial port to the battery $[80(\mathrm{AH}), 12(\mathrm{~V})]$ load bank to record the current and voltage readings (power) round the clock. The comparison is carried during different weather conditions and for different seasons.

\section{A. Experimental Results During a Clear Day}

A database for the recorded current and voltage readings is created. The fixed system values are averaged per each hour from $7 \mathrm{am}$ to $7 \mathrm{pm}$ for a cold sunny day as shown in Table 1 . The tracking system data are recorded in Table 2 . The gain in the average power in this case is around 10.49 watts per each hour. However to calculate the net gain of the tracking system, power lost is also observed and calculated. The motors are normally active for around 10 seconds for every one hour of duty, so the average value of the power per hour loss came to be around 0.5 watt per hour. This yields a net gain of nearly 10 watts per hour i.e. $24 \%$ more power is generated using the tracking system.

Table I. - Fixed System Data

\begin{tabular}{|c|c|c|c|}
\hline Hour & Voltage (V) & Current (A) & Power (W) \\
\hline $07 \mathrm{am}$ & 13.25 & 1.1 & 14.575 \\
\hline $08 \mathrm{am}$ & 14.11 & 1.7 & 23.987 \\
\hline $09 \mathrm{am}$ & 15.67 & 2.8 & 43.876 \\
\hline $10 \mathrm{am}$ & 15.98 & 3 & 47.94 \\
\hline $11 \mathrm{am}$ & 16.25 & 3.2 & 52 \\
\hline $12 \mathrm{pm}$ & 15.93 & 3.62 & 57.6666 \\
\hline $01 \mathrm{pm}$ & 16.1 & 3.6 & 57.96 \\
\hline $02 \mathrm{pm}$ & 15.67 & 3.6 & 56.412 \\
\hline $03 \mathrm{pm}$ & 15.67 & 3.49 & 54.6883 \\
\hline $04 \mathrm{pm}$ & 15.54 & 3.1 & 48.174 \\
\hline $05 \mathrm{pm}$ & 15.4 & 2.4 & 36.96 \\
\hline $06 \mathrm{pm}$ & 15.4 & 1.8 & 27.72 \\
\hline $07 \mathrm{pm}$ & 14.1 & 0.9 & 12.69 \\
\hline \multicolumn{3}{|c|}{ Average Power per Hour (W/hr.) } & 41.12684 \\
\hline
\end{tabular}

The power distribution graph is plotted against the $7 \mathrm{am}-7 \mathrm{pm}$ period as shown in Fig. 11. It is quite obvious that the percentage increase in power is focused at the early and afternoon hours. After all, the fixed panel at these periods of the day will not be erected in the optimum irradiation receiving position. Similar results are obtained for different days of the year and for different weather conditions (hot, and cold) where the maximum power gain reached, with this type of tracking mechanism, is $28 \%$ more than a fixed one.
Table II. - Tracking System Data

\begin{tabular}{|l|l|l|l|}
\hline Hour & Voltage (V) & Current (A) & Power (W) \\
\hline $07 \mathrm{am}$ & 15.2 & 2.5 & 38 \\
\hline $08 \mathrm{am}$ & 15.54 & 3.2 & 49.728 \\
\hline $09 \mathrm{am}$ & 15.97 & 3.3 & 52.701 \\
\hline $10 \mathrm{am}$ & 16.21 & 3.39 & 54.9519 \\
\hline $11 \mathrm{am}$ & 16.35 & 3.24 & 52.974 \\
\hline $12 \mathrm{pm}$ & 15.94 & 3.74 & 59.6156 \\
\hline $01 \mathrm{pm}$ & 16.08 & 3.61 & 58.0488 \\
\hline $02 \mathrm{pm}$ & 15.67 & 3.61 & 56.5687 \\
\hline $03 \mathrm{pm}$ & 15.67 & 3.53 & 55.3151 \\
\hline $04 \mathrm{pm}$ & 15.54 & 3.53 & 54.8562 \\
\hline $05 \mathrm{pm}$ & 15.54 & 3.37 & 52.3698 \\
\hline $06 \mathrm{pm}$ & 15.4 & 3.42 & 52.668 \\
\hline $07 \mathrm{pm}$ & 15.1 & 2.2 & 33.22 \\
\hline Average Power per Hour (W/hr.) & 51.6167 \\
\hline
\end{tabular}

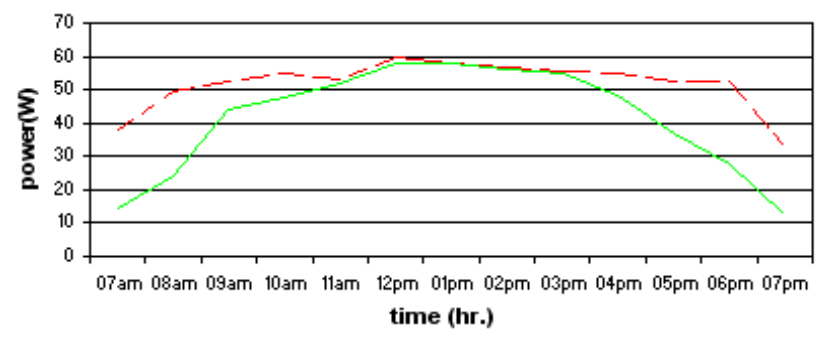

Fig. 11: Power distribution over the duty hrs period

\section{B. Experimental Results During Cloudy Weather}

The system is also tested under both partially and totally cloudy weather conditions. In case of total shade, the microcontroller collects the data from the phototransistors, deactivates the tracking system and enters a standby mode. Once the sun shines and rays strike the phototransistors, the system reorients into the optimum position.

In case of partial shading, the system will keep track of the sun as long as the difference in the phototransistors readings is sensible (refer to algorithm). Otherwise it goes to the standby mode. Fig. 12 shows two power-versus-time graphs for two different days of the year. The dotted graph represents the tracking system power while the solid one represents the fixed system. The top graph is captured during the morning-noon time while the other is during the afternoon. This is due to the availability of such weather condition during these days. Again the tracking system proved its benefit and the power gain varied from $20 \%$ to $25 \%$. 


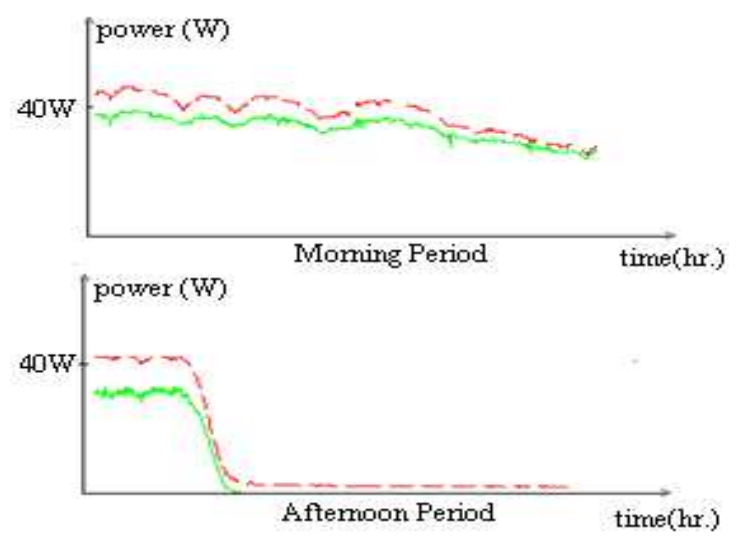

Fig. 12: captured during partial shading conditions.

\section{Conclusion}

A solar tracking system can easily increase the solar energy absorbed compared to a fixed system. However to carry on a fair comparison with a fixed system, the inclination angle of the fixed panel must be considered and the orientation of the fixed panel should be changed once or twice a season according to the summer and winter sun arch.

The power loss due to the control electronic circuit and the antenna motors is very little compared to the power gained form the tracking system; after all the motors are only active for few seconds while correcting the position of the panel with respect to the sun. Finally the motors and mechanical structure cost $(250 \$$ in this case) will be retrieved within no time from the extra power generated.

\section{Acknowledgment}

The authors wish to thank Mr. Antoine Al Asal, Siblin Training Center, for his technical services and assistance in fabricating the tracking system.

\section{References}

[1]. R. A. Bentley, "Global Oil Depletion-Methodologies and Results", Proc. 3rd Int. Workshop on Oil and Gas Depletion, Berlin, Germany, 2004; pp. 25-26.

[2]. K. Kurokawa, L. Kazamerski, B. McNelis, "Message from the Conference Chair and Vice Chairs", Proceedings of 3rd World Conference on Photovoltaic Energy Conversion, Osaka, Japan, May 11-18, 2003.

[3]. R. Hug, "Solar Power from the Desert rather than Desert in Germany: renewable energy in a trans-European context",
February 23, 2007, available at www.solarserver.de/solarmagazin/index-e.html.

[4]. M.A. Ghias, K.S. Karimov, S.I.A. Termizi, M.J. Mughal, M.A. Saqib, I.H. Kazmi, "A Photo-Voltaic System with Load Control", ICEE07, April 11-12, 2007, Int. Conference on Elect. Engineering.

[5]. T. Jinayim, S. Arunrungrasmi, T. Tanitteerapan, N. Mungkung, "Highly Efficient Low Power Consumption Tracking Solar Cells for White LED-Based Lighting System", International Journal Of Electrical, Computer, And Systems Engineering, Volume 1 Number 2, 2007 ISSN 1307-5179.

[6]. K.S. Karimov, J.A. Chattha, M.M. Ahmed et al., Journal of References, Academy of Sciences of Tajikistan, Vol. XLV, No.9, 2002; pp. 75-83.

[7]. A.A. Khalil, M. El-Singaby, "Position control of sun tracking system.;

Circuits and Systems", Proceedings of the 46th IEEE International Midwest Symposium, Vol. 3, December 27-30, 2003 , pp. $1134-1137$.

[8]. W. Dankoff, "Glossary of Solar Water Pumping Terms and Related Components", available at www.conergy.us/Desktopdefault.aspx/tabid-332/449_read$3816 /$.

[9]. T. Hiyama, S. Kouzuma, T. Imakubo, "Identification of Optimal Operating Point of PV Modules Using Neural Network for Real Time Maximum Power Tracking Control", IEEE Trans. Energy Conversion, 10, 1995, pp. 360-367.

[10].A. Baz, A. Sabry, A. Mobarak, S. Morcos, "On the Tracking Error of a Self-contained Solar Tracking System", Trans. ASME, Journal of Solar Energy Engineering, 106, 1984, pp. 416-422.

[11].P. T. Huynh, and B. H. Cho, "Design and analysis of a regulated peak-power tracking system", IEEE Trans. Aerospace Electronic Systems, Vol.35, 1999, pp. 84-92.

[12].A. M. Sharan, M. Prateek, "Automation of Minimum Torquebased Accurate Solar Tracking Systems Using Microprocessors", Journal of the Indian Institute of Science, Sept.-Oct. 2006, Vol.86, pp. 415-437.

[13].A.B. Maish, "Performance of a self-aligning solar array tracking controller", Photovoltaic Specialists Conference, Conference Record of the Twenty First IEEE, May 21-25, 1990, Vol.2, pp. $864-869$. 